\title{
13-cis Retinoic Acid Inhibits Growth of Adult T Cell Leukemia Cells and Causes Apoptosis; Possible New Indication for Retinoid Therapy
}

\author{
Yasuhiro Maeda, Jun-ichi Mryatake, Hiroshi Sono, Mitsuhiro Matsuda, \\ Yoichi TATSUmi, Fusanari Horiuchi, Kiyohiro IRIMAJIRI and Atsushi Horiuchi
}

\begin{abstract}
We evaluated the effects of 13-cis retinoic acid (13-cis RA) on the growth of peripheral blood mononuclear cells (PBMC) obtained from 12 patients with adult $T$ cell leukemia (ATL). In general, 13-cis RA potently inhibited the growth of PBMC from ATL patients. However, the sensitivity of the cells to 13-cis RA-induced growth inhibition varied among the patients. The ATL patients fell into three groups (hypersensitive, sensitive and resistant to 13-cis RA) according to the percent reduction of ${ }^{3} \mathrm{H}$-thymidine incorporation before and after treatment with 13 -cis RA. Agarose gel electrophoresis of total genomic DNA from a patient sensitive to 13-cis RA provided evidence of the DNA fragmentation indicative of apoptosis. The ability of 13-cis RA to induce apoptosis in PBMC from ATL patients suggests that retinoids may be useful in the treatment of ATL.
\end{abstract}

(Internal Medicine 35: 180-184, 1996)

Key words: retinoid, growth inhibition, DNA fragmentation, human T lymphotropic virus type I $($ HTLV-I)(+)T lymphocytes

\section{Introduction}

Retinoids can influence the growth and differentiation of various hematopoietic progenitor cells $(1,2)$. Porfiri et al reported that retinoic acid (RA) induces subtle changes in inositol lipid-derived second messengers and that these changes might contribute to the agent's effects on growth and differentiation (3). Retinoids are important in coordinating the complex interaction of the cells and soluble factors that constitute the immune and hematopoietic system.

For editorial comment, see p 167.

Adult T cell leukemia (ATL) is a neoplasma of mature Tlymphocytes that is caused by the human $\mathrm{T}$ lymphotropic virus type I (HTLV-I) (4-6) and is characterized by the excessive expression of the $55 \mathrm{kD}$ chain of the interleukin 2 receptor (IL2R/p55) (Tac) (7-9). IL-2R/p55 (Tac, CD25) expression is induced by the ATL-derived factor (ADF) (10-12), which is homologous to thioredixin (TRX) (13). In addition to its effect on IL-2R/p55 (Tac, CD25), ADF also reduces active oxygen species (13). It has been reported that 13-cis retinoic acid (13cis RA) can inhibit ADF/TRX reductase activity (14). Due to this interaction between 13-cis RA and the ADF/TRX system, we examined the effects of 13-cis RA on the cell growth of peripheral blood mononuclear cells (PBMC) from patients with ATL. Using ${ }^{3} \mathrm{H}$-thymidine incorporation and DNA fragmentation analysis, we investigated whether 13-cis RA induces growth inhibition and apoptosis in the PBMC of ATL patients. The findings indicate that 13-cis RA may be useful in the treatment of ATL patients.

\section{Materials and Methods}

\section{Patients}

Twelve Japanese patients diagnosed as ATL were selected for this study. Ten of the patients had the acute type of ATL, and 2 had the chronic type of ATL (Table 1). The diagnosis of ATL was performed according to the clinical features and hematological findings, including the morphological characteristics, cell surface phenotypes and serum antibodies against HTLV-I associated antigens. They were classified as acute and chronic types of ATL according to the criteria of the Lymphoma Study Group (15). The clinical characteristics of these patients are summarized in Table 1. Five normal individuals were randomly selected for this study.

From the Third Department of Internal Medicine, Kinki University School of Medicine, Osaka-sayama

Received for publication July 31, 1995; Accepted for publication November 30, 1995

Reprint requests should be addressed to Dr. Yasuhiro Maeda, the Third Department of Internal Medicine, Kinki University School of Medicine, 377-2 Ohnohigashi, Osaka-sayama, Osaka 589 
Table 1. Hematological and Immunological Data of ATL Patients. Twelve Patients were Diagnosed as ATL Based on the Accepted Criteria for Clinical, Hematological, and Laboratory Parameters.

\begin{tabular}{|c|c|c|c|c|c|c|c|c|c|c|c|}
\hline $\begin{array}{c}\text { Patient } \\
\text { No. }\end{array}$ & $\begin{array}{c}\text { Age } \\
\text { (years/sex) }\end{array}$ & $\begin{array}{l}\text { WBC } \\
(/ \mu 1)\end{array}$ & $\begin{array}{c}\text { ATL cells } \\
(\%)\end{array}$ & $\begin{array}{c}\mathrm{Ca} \\
(\mathrm{IU} / l)\end{array}$ & $\begin{array}{l}\mathrm{LDH} \\
(\mathrm{IU} / l)\end{array}$ & $\begin{array}{l}\text { CD3 } \\
(\%)\end{array}$ & $\begin{array}{l}\text { CD4 } \\
(\%)\end{array}$ & $\begin{array}{l}\text { CD8 } \\
(\%)\end{array}$ & $\begin{array}{c}\mathrm{CD} 25 \\
(\%)\end{array}$ & $\begin{array}{l}\text { HTLV-1 } \\
\text { (titer) }\end{array}$ & Type \\
\hline 1. & $45 \mathrm{~F}$ & 14,300 & 87.5 & 8.5 & 367 & 91.5 & 97.4 & 5.2 & 90.5 & 1,024 & Acute \\
\hline 2. & $43 \mathrm{M}$ & 13,600 & 20.4 & 9.2 & 252 & 91.9 & 88.0 & 6.8 & 78.1 & 6,553 & Acute \\
\hline 3. & $34 \mathrm{M}$ & 6,200 & 2.0 & 13.1 & 295 & 64.4 & 57.6 & 16.4 & 60.5 & 2,048 & Acute \\
\hline 4. & $45 \mathrm{~F}$ & 4,600 & 86.5 & 8.4 & 440 & 91.5 & 97.4 & 5.2 & 90.5 & 1,024 & Acute \\
\hline 5. & $43 \mathrm{M}$ & 16,000 & 18.0 & 9.4 & 311 & 91.9 & 88.0 & 6.8 & 78.1 & 65,536 & Acute \\
\hline 6. & $81 \mathrm{~F}$ & 1,300 & 86.2 & 7.4 & 468 & 93.1 & 94.8 & 4.9 & 91.4 & 4,096 & Acute \\
\hline 7. & $64 \mathrm{~F}$ & 4,000 & 4.0 & 8.7 & 700 & ND & ND & ND & 30.5 & 16,384 & Acute \\
\hline 8. & $44 \mathrm{~F}$ & 4,800 & 2.7 & 9.7 & 196 & ND & ND & ND & 5.8 & 4,096 & Acute \\
\hline 9. & $47 \mathrm{M}$ & 10,600 & 25.7 & 9.0 & 484 & ND & 87.6 & 6.6 & 25.7 & 65,536 & Chronic \\
\hline 10. & $48 \mathrm{M}$ & 25,500 & 52.5 & 9.1 & ND & 96.2 & 85.8 & 7.6 & 85.7 & 65,536 & Acute \\
\hline 11. & $69 \mathrm{M}$ & 15,200 & 28.7 & 8.8 & 286 & ND & 90.3 & 4.9 & 44.7 & 256 & Chronic \\
\hline 12. & $58 \mathrm{~F}$ & 25,600 & 80.9 & 7.8 & 514 & 4.4 & 94.2 & 1.9 & 98.2 & 4,096 & Acute \\
\hline
\end{tabular}

ND: not done, WBC: white blood cells, ATL cells: adult T cell leukemia cells, LDH: lactate dehydrogenase (normal range: 100-225 IU/l), HTLV-1: The titer of HTLV-I antibodies in serum was measured by the passive agglutination method.

\section{Retinoid}

13-cis RA was obtained from Sigma (St. Louis, MO, USA). The retinoid was handled with care according to the method of Dawson and Hobbs (16).

\section{Cell culture}

PBMC from ATL patients were collected from heparinized peripheral blood (PB) by the Ficoll-Paque gradient centrifugation method at the time of diagnosis before chemotherapy. The PBMC $\left(2 \times 10^{5} /\right.$ well $)$ were suspended in $200 \mu$ l RPMI 1640 medium (Nissui Pharmaceutical Co. Ltd., Tokyo, Japan) containing $10 \%$ fetal calf serum (FCS) (JRH Biosciences, Lenexa, $\mathrm{KS}$, USA) and were cultured for 48 hours at $37^{\circ} \mathrm{C}$ in a 96-well flat-bottomed microplate. When adding 13-cis RA to the cells, the ethanol stock solution of 13-cis RA was diluted with RPMI 1640 containing $10 \%$ FCS.

\section{Cell growth assay}

Cell growth was determined by ${ }^{3} \mathrm{H}$-thymidine incorporation. Briefly, one microcurie of ${ }^{3} \mathrm{H}$-thymidine (Amersham, Buckinghamshire, UK) was pulsed for the last 4 hours. ${ }^{3} \mathrm{H}$-thymidine incorporation was measured by a liquid scintillation counter.

\section{Genomic DNA extraction and agarose gel electrophoresis}

After culture with several concentrations of 13-cis RA for 48 hours, genomic DNA was extracted from the cells as described previously (17). Briefly, after washing with ice-cold PBS, the cells were resuspended in $0.5 \mathrm{ml}$ digestion buffer $(100 \mathrm{mM}$ $\mathrm{NaCl}, 10 \mathrm{mM}$ Tris-Cl pH 8.0, 25 mM EDTA pH 8.0, 0.5\% SDS, $0.1 \mathrm{mg} / \mathrm{ml}$ proteinase $\mathrm{K}$ ). The cells were then incubated with shaking at $50^{\circ} \mathrm{C}$ for 12 hours. After phenol/chloroform extraction, genomic DNA was isolated by ethanol precipitation. The genomic DNA was dissolved with distilled water (DW) and subjected to electrophoresis on a 1.5\% agarose gel (Pharmacia Biotech, Uppsala, Sweden). After staining with ethidium bromide, DNA bands were visualized by UV irradiation.

\section{Results}

\section{Growth inhibition of ATL cells by 13-cis RA}

PBMC isolated from the 12 ATL patients were incubated with several concentrations $\left(10^{-9} \mathrm{M}\right.$ to $\left.10^{-5} \mathrm{M}\right)$ of 13 -cis RA. After 48 hours, ${ }^{3} \mathrm{H}$-thymidine incorporation into the cells was measured as an indicator of growth rate. Figure 1 shows the effect of 13-cis RA on the PBMC from ATL patients. The most significant growth inhibition by 13-cis RA is shown for each case. The sensitivity of the PBMC to 13-cis RA is expressed as $\%$ reduction of ${ }^{3} \mathrm{H}$-thymidine incorporation compared to untreated cells. The 12 ATL patients were divided into three groups (Fig. 2): resistant to 13-cis RA (less than 30\% reduction), sensitive to 13 -cis RA (reduction between $30 \%$ and $70 \%$ ) and hypersensitive to 13 -cis RA (reduction greater than 70\%). We investigated whether there was any correlation between the sensitivity to 13-cis RA and other clinical parameters of the disease. However, no such correlation existed. When normal PBMC were cultured with various concentrations of 13-cis RA, as shown in Fig. 3, no significant growth inhibition was observed.

\section{Induction of apoptosis of ATL cells by retinoic acid}

To determine whether incubation with 13-cis RA could inhibit cell growth as well as cause apoptosis, we assessed the fragmentation of genomic DNA in PBMC treated with different concentrations of 13-cis RA. Genomic DNA was isolated from 


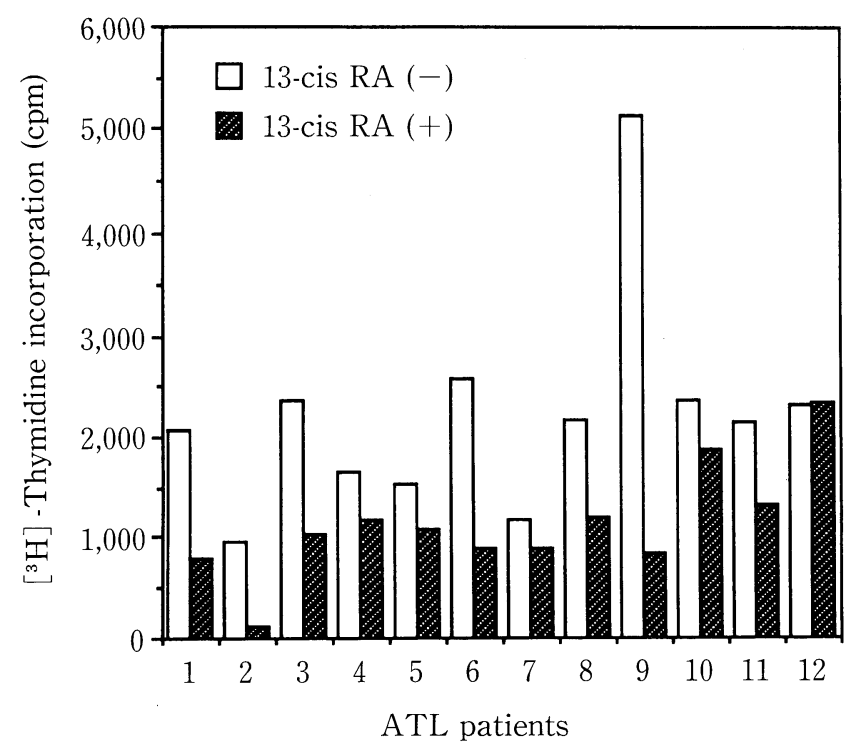

Figure 1. The effects of 13-cis RA on the growth of PBMC from ATL patients. Twelve samples (PBMC) obtained from ATL patients were cultured with or without several concentrations $\left(10^{-9} \mathrm{M}\right.$ to $\left.10^{-5} \mathrm{M}\right)$ of 13 -cis RA for 48 hours and the growth activity was determined by ${ }^{3} \mathrm{H}$-thymidine incorporation. The values of ${ }^{3} \mathbf{H}$-thymidine incorporation represented the mean value of triplicate cultures.

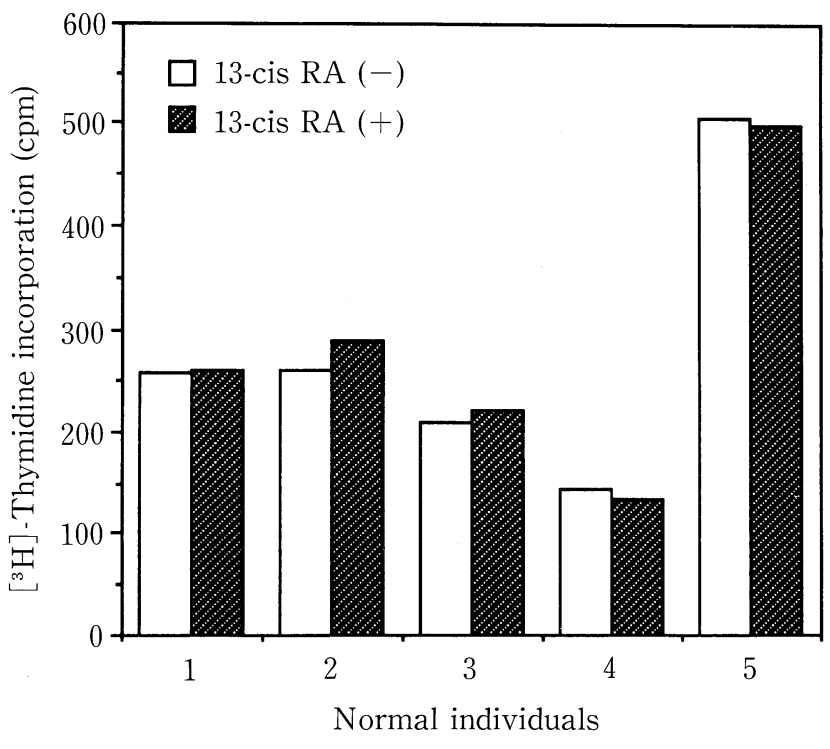

Figure 3. The effects of 13-cis RA from normal PBMC.PBMC obtained from 5 normal individuals were cultured with or without several concentrations $\left(10^{-9} \mathrm{M}\right.$ to $\left.10^{-5} \mathrm{M}\right)$ of 13 -cis $\mathrm{RA}$, and the sensitivity of 13-cis RA was determined by ${ }^{3} \mathrm{H}$-thymidine incorporation. The values of ${ }^{3} \mathrm{H}$-thymidine uptake were the mean value of triplicate cultures.

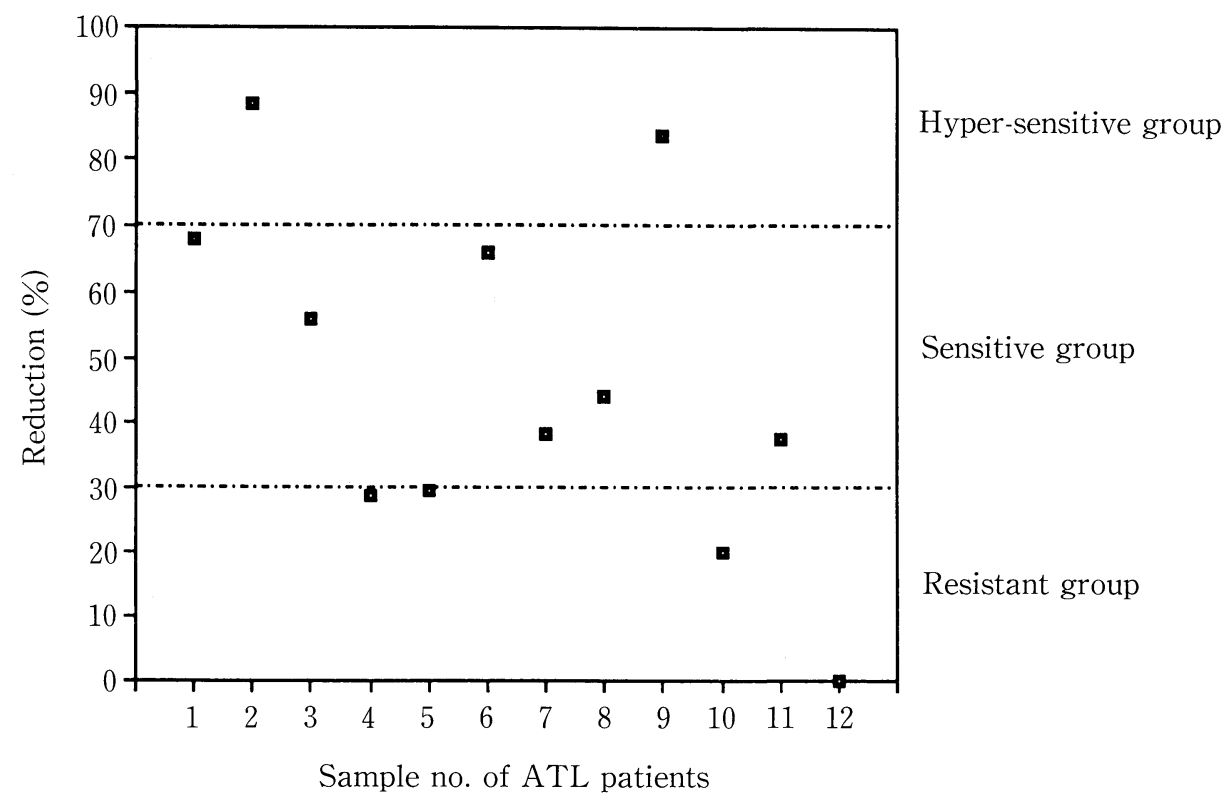

Figure 2. The sensitivity of PBMC from ATL patients to 13-cis RA. The sensitivity of PBMC to 13-cis RA was measured as \% reduction ${ }^{3} \mathrm{H}$-thymidine incorporation after incubation with 13-cis RA for $\mathbf{4 8}$ hours, compared with untreated cells. The reduction rate (\% reduction) was calculated as follows: $\%$ reduction $=\left(\right.$ basal ${ }^{3} \mathbf{H}$-thymidine incorporation) - $\left({ }^{3} \mathbf{H}\right.$-thymidine incorporation added 13 -cis RA)/(basal ${ }^{3} \mathbf{H}$-thymidine incorporation) $\times 100$. The values of ${ }^{3} \mathrm{H}$-thymidine incorporation in above calculation were the mean value of triplicate cultures. 


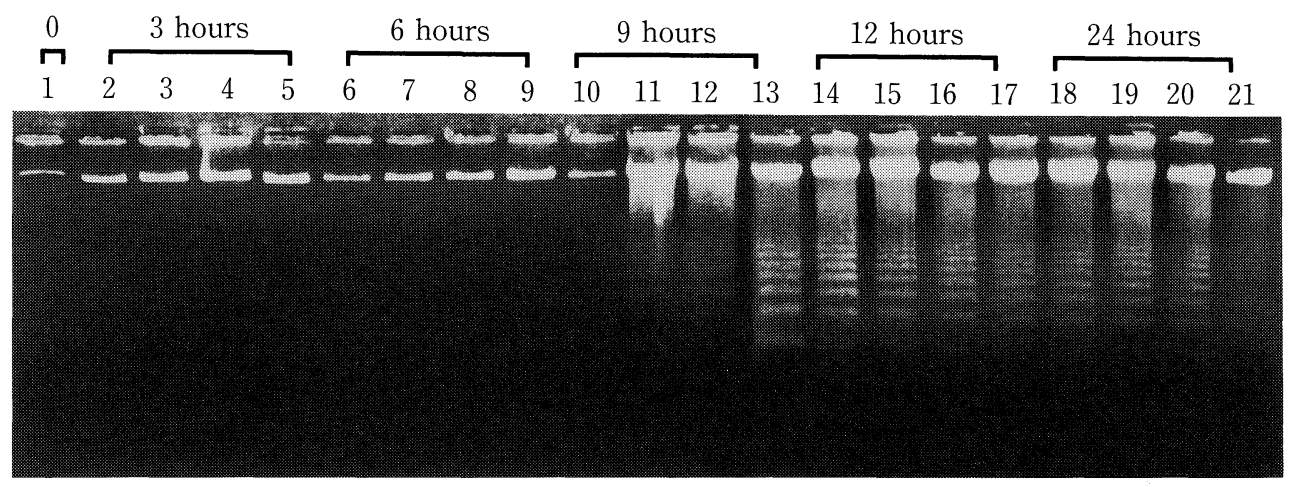

Figure 4. Electrophoretic pattern of genomic DNA isolated from ATL cells after incubation with 13-cis RA. PBMC isolated from ATL patient no. 6 were incubated with or without 13-cis RA $\left(10^{-5} \mathrm{M}, 10^{-7} \mathrm{M}\right.$ and $\left.10^{-9} \mathrm{M}\right)$. Genomic DNA was extracted after 0 hour, 3 hours, 6 hours, 9 hours, 12 hours and 24 hours culture and analyzed by $1.5 \%$ agarose gel electrophoresis.

Lane 1: freshly collected PBMC. Lane 2: 3 hour culture without 13-cis RA. Lane 3: 3 hour culture with $10^{-5} \mathrm{M}$ 13-cis RA. Lane 4: 3 hour culture with 10 $^{-7} \mathrm{M}$ 13-cis RA. Lane 5: 3 hour culture with $10^{-9} M$ 13-cis RA. Lane 6: 6 hour culture without 13-cis RA. Lane 7: 6 hour culture with 10-5 M 13cis RA. Lane 8: 6 hour culture with $10^{-7} \mathrm{M}$ 13-cis RA. Lane 9: 6 hour culture with $10^{-9} \mathrm{M}$ 13-cis RA. Lane 10: 9 hour culture without 13-cis RA. Lane 11: 9 hour culture with $10^{-5}$ M 13-cis RA. Lane 12: 9 hour culture with $10^{-7}$ M 13-cis RA. Lane 13: 9 hour culture with 10-9 M 13-cis RA. Lane 14: 12 hour culture without 13-cis RA. Lane 15: 12 hour culture with $10^{-5} \mathrm{M}$ 13-cis RA. Lane 16: 12 hour culture with $10^{-7} \mathrm{M}$ 13-cis RA. Lane 17: 12 hour culture with $10^{-9} \mathrm{M}$ 13-cis RA. Lane 18: 24 hour culture without 13-cis RA. Lane 19: 24 hour culture with $10^{-5} \mathrm{M}$ 13-cis RA. Lane 20: 24 hour culture with $10^{-7}$ M 13-cis RA. Lane 21: 24 hour culture with $10^{-9} \mathrm{M}$ 13-cis RA.

the PBMC of patient no. 6 that were incubated with and without several concentrations for several culture periods up to 24 hours. The fragmentation status of the DNA was assessed by $1.5 \%$ agarose gel electrophoresis.

As shown in Fig. 4, no DNA fragmentation was apparent in freshly collected PBMC and for up to 6 hours in the absence or presence of 13-cis RA. After 9 hours culture with $10^{-5} \mathrm{M}, 10^{-7} \mathrm{M}$ or $10^{-9} \mathrm{M} 13$-cis RA, however, substantial DNA fragmentation was evident in the PBMC. DNA fragmentation indicative of spontaneous apoptosis was also observed after 12 hours and 24 hours of incubation with 13-cis RA.

\section{Discussion}

The Tlymphocytes of patients with ATL are immunologically characterized by the abnormal expression of the $55 \mathrm{kD}$ chain of the interleukin 2 receptor (IL-2R/p55) (Tac, CD25), which may be involved in the genesis of ATL (7-9). ADF has been reported to induce IL-2R/p55 (Tac, CD25) expression (10-12). Cloned cDNA of human ADF has a strong homology with TRX (13), a coenzyme that catalyzes the reduction of proteins in prokaryotic systems (14). ADF, in turn, can scavenge free radicals as well as exhibit the reducing activity of an active oxygen species. 13-cis RA has been reported to inhibit TRX reductase activity (14) and thus may also interfere with ADF activity.

Based on this hypothesis, we studied the effects of 13-cis RA on the growth of PBMC obtained from ATL patients. Sensitiv- ity to 13-cis RA was determined by measuring the percent reduction of ${ }^{3} \mathrm{H}$-thymidine incorporation. This approach provided a good index of the sensitivity to 13 -cis RA. The 12 patients in this study fell into three groups with respect to their sensitivity to 13-cis RA. Although PBMC from ATL patients with a high percentage of ATL cells seemed to be more sensitive to 13-cis RA than those from ATL patients with a low percentage of ATL cells, no tight correlation was seen between the sensitivity to 13-cis RA and the clinical characteristics of the patients as presented in Table 1. We suggest, however, that the three patient groups may have differed in their level of ADF production, and that the patients whose PBMC were more sensitive to 13-cis RA produced lower ADF levels than the patients whose PBMC were resistant to 13-cis RA. This hypothesis was supported by a preliminary study that used subclones of the HTLV-I(+) T cell line HUT102: retinoid-resistant HUT102 clones produced higher ADF levels than the retinoid-sensitive HUT102 clones (Miyatake J et al, manuscript in submission).

To investigate the mechanism through which 13-cis RA induces growth inhibition in ATL cells, we analyzed the integrity of the genomic DNA from one ATL patient in the sensitive group before and after its incubation with 13-cis RA. Incubation periods of more than 9 hours resulted in significant DNA fragmentation, indicating that 13-cis RA could lead to apoptosis. This programmed cell death may inhibit the growth of ATL cells. This phenomenon of inducible DNA fragmentation by 13-cis RA was observed in PBMC of the sensitive and hyper- 


\section{MAEDA et al}

sensitive groups.

In contrast, as shown in Fig. 3, 13-cis RA had no effect on the growth of normal PBMC. Furthermore, DNA fragmentation induced by 13-cis RA was not observed in normal PBMC, and also in PBMC from ATL patients of the resistant group (data not shown). We therefore conclude that 13-cis RA may be useful for patients with ATL, as well as for those with malignant diseases $(18,19)$.

Acknowledgements: The authors thank Ms. Y. Hoshino and Ms. T. Tsuji for technical support, and to Ms. S. Yoshida, A. Yamada, and M. Nakagawa for preparing the manuscript.

\section{References}

1) Zauli G, Visani G, Vitale M, et al. All-trans retinoic acid shows multiple effects on the survival, proliferation and differentiation of human fetal CD34+ haemopoietic progenitor cells. Br J Haematol 90: 274, 1995.

2) Tobler A, Dawson MI, Koeffler HP. Retinoid. Structure-function relationship in normal and leukemic hematopoiesis in vitro. J Clin Invest 78: 303, 1986

3) Porfiri E, Hoffbrand AV, Wickremasinghe RG. Retinoic acid-induced granulocytic differentiation of HL-60 human promyelocytic leukemia cells is preceded by down regulation of autonomous generation of inositol lipid-derived second messengers. Blood 78: 1069, 1991.

4) Yodoi J, Takatsuki K, Masuda T. Two cases of T-cell chronic leukemia in Japan. N Engl J Med 290: 572, 1974.

5) Hinuma $Y$, Nagata $K$, Hanaoka $M$, et al. Adult $T$ cell leukemia: antigen in an ATL cell line and detection of antibodies to the antigen in human sera. Proc Natl Acad Sci USA 78: 6476, 1981.

6) Poiez BZ, Ruscetti FW, Gazdar AF, Bunn PA, Minna JD, Gallo RC. Detection and isolation of type-C retrovirus particles from fresh and culture lymphocytes of a patient with cutaneous T cell-lymphoma. Proc Natl Acad Sci USA 77: 7415, 1980.
7) Uchiyama $\mathrm{T}$, Hori $\mathrm{T}$, Tsuda $\mathrm{M}$, et al. Interleukin-2 receptor (Tac antigen) expressed on adult T cell leukemia. J Clin Invest 76: 446, 1985.

8) Yodoi J, Tagaya Y, Okada M, et al. IL-2 receptor gene regulation by cytokines: role of ATL-derived factor(s) (ADFs) in ATL. Acta Histochem Cytochem 19: 719, 1986.

9) Yodoi J, Uchiyama T. IL-2 receptor dysfunction and adult T-cell leukemia. Immunol Rev 92: 135, 1986

10) Teshigawara $K$, Maeda $M$, Nishino $K$, et al. Adult $T$ cell leukemia cells produce a lymphokine that augment interleukin 2 receptor expression. $\mathrm{J}$ Mol Cell Immunol 2: 17, 1985.

11) Okada M, Maeda M, Tagaya $Y$, et al. TCGF(IL-2)-receptor inducing factor(s). II. Possible role of ATL-derived factor (ADF) on constitutive IL-2 receptor expression of HTLV-I(+) T cell line. J Immunol 135: 3995 , 1985.

12) Tagaya $Y$, Okada $M$, Sugie $K$, et al. IL-2 receptor/Tac(p55) inducing factor: purification and characterization of ATL-derived factor (ADF). $\mathbf{J}$ Immunol 140: 2613, 1988.

13) Tagaya $Y$, Maeda $Y$, Mitsui A, et al. ATL-derived factor (ADF), an IL$2 \mathrm{R} / \mathrm{Tac}$ inducer homologous to thioredoxin: possible involvement of dithiol-reduction in the IL-2-receptor induction. EMBO J 8: 757, 1989.

14) Schallreuter KU, Wood JM. The stereospecific suicide inhibition of human melanoma thioredoxin reductase by 13 -cis retinoic acid. Biochem Biophys Res Commun 160: 573, 1990.

15) Shimoyama M, The Lymphoma Study Group (1984-1987). Diagnostic criteria and classification of clinical subtype of adult T-cell leukemialymphoma. Br J Haematol 79: 428, 1991.

16) Dawson MI, Hobbs PD. Synthetic retinoic acid analogs: handling and characterization. Methods Enzymol 189: 15, 1990.

17) Gross-Bellard $M$, Oudet $P$, Chambon $P$. Isolation of high-molecularweight DNA from mammalian cells. Eur J Biochem 36: 32, 1973.

18) Goodman DS. Vitamin A and retinoid in health and disease. N Engl J Med 310: 1023,1984

19) Clamon G, Chabot GG, Valeriote F, et al. Phase I study and pharmacokinetics of weekly high-dose 13-cis-retinoic acid. Cancer Res 45: 1874 , 1985. 